\title{
Biological and therapeutic activities, and anticancer properties of curcumin (Review)
}

\author{
DONATELLA PERRONE, FATIMA ARDITO, GIOVANNI GIANNATEMPO, MARIO DIOGUARDI, \\ GIUSEPPE TROIANO, LUCIO LO RUSSO, ALFREDO DE LILLO, LUIGI LAINO and LORENZO LO MUZIO
}

Department of Clinical and Experimental Medicine, Foggia University, Foggia 71122, Italy

Received April 14, 2015; Accepted July 14, 2015

DOI: $10.3892 / \mathrm{etm} .2015 .2749$

\begin{abstract}
Curcumin (diferuloylmethane) is a polyphenol derived from the Curcuma longa plant. Curcumin has been used extensively in Ayurvedic medicine, as it is nontoxic and exhibits a variety of therapeutic properties, including antioxidant, analgesic, anti-inflammatory and antiseptic activities. Recently, certain studies have indicated that curcumin may exert anticancer effects in a variety of biological pathways involved in mutagenesis, apoptosis, tumorigenesis, cell cycle regulation and metastasis. The present study reviewed previous studies in the literature, which support the therapeutic activity of curcumin in cancer. In addition, the present study elucidated a number of the challenges concerning the use of curcumin as an adjuvant chemotherapeutic agent. All the studies reviewed herein suggest that curcumin is able to exert anti-inflammatory, antiplatelet, antioxidative, hepatoprotective and antitumor activities, particularly against cancers of the liver, skin, pancreas, prostate, ovary, lung and head neck, as well as having a positive effect in the treatment of arthritis.
\end{abstract}

\section{Contents}
1. Introduction
2. Chemical composition
3. Anti-inflammatory activity
4. Effect on arthritis
5. Antiplatelet activity
6. Antioxidant activity
7. Hepatoprotective action
8 Anticancer activity
9. Liver cancer
10. Skin carcinogenesis

Correspondence to: Professor Lorenzo Lo Muzio, Department of Clinical and Experimental Medicine, Foggia University, Via Rovelli 48, Foggia 71122, Italy

E-mail: 1lomuzio@tin.it

Key words: curcumin, nutraceutical, cancer, anti-inflammatory activity, anticancer agents
11. Pancreatic cancer
12. Prostate cancer
13. Ovarian cancer
14. Lung cancer
15. Head and neck cancer
16. Conclusion

\section{Introduction}

Curcumin [1,7-Bis(4-hydroxy-3-methoxyphenyl)-1,6-hep tadiene 3,5-dione] is among the most extensively studied naturally-derived therapeutic products in recent decades, due to its various properties. It is the primary biologically active curcuminoid of Curcuma longa, a herbaceous perennial plant belonging to the ginger family (Zingiberaceae) (1).

Curcuma longa, commonly known as turmeric, is native to South Asia, India and Indonesia and is predominantly grown in South India $(2,3)$. The root and rhizome (underground stem) of Curcuma longa is crushed and powdered into ground turmeric. Ground turmeric is used worldwide as a seasoning and as a key ingredient in curry. Curry contains $\sim 2 \%$ curcumin, which was first identified in 1910 by Miłobȩdzka et al (4). Furthermore, curcumin is responsible for the yellow color of the spice, in addition to the majority of the therapeutic effects attributed to turmeric $(3,5)$. The other two curcumoids obtained from Curcuma longa are desmethoxycurcumin (DMC) and bis-desmethoxycurcumin (BDMC; Fig. 1). In addition, turmeric contains a number of volatile oils (e.g. zingiberone, atlantone and tumerone), sugars, resins and proteins. However, other than curcumin, turmeric contains no known agents with anti-inflammatory and anti-proliferative activity (6).

Following its extraction and purification, curcumin is used for its attributed medicinal properties as a natural treatment for numerous diseases. In Ayurvedic medicine, turmeric has been used for centuries for its medicinal properties (7) and has been administered through various routes, including topically, orally and by inhalation. It is well known that the curcumin exerts certain antioxidant, analgesic, anti-inflammatory and antimalarial properties (7-15).

Furthermore, curcumin is considered to be pharmacologically safe (9), and is classed as safe for human consumption by the US Food and Drug Administration (16). It is widely consumed as a condiment without any known side effects. 
<smiles>COc1cc(/C=C/C(=O)CC(=O)/C=C/c2ccc(O)c(OC)c2)ccc1O</smiles>

B<smiles>COc1cc(/C=C/C(=O)CC(=O)/C=C/c2ccc(O)cc2)ccc1O</smiles>

C

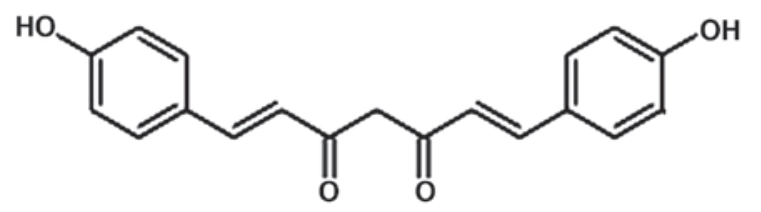

Figure 1. Primary extracts of the Curcuma longa plant. (A) Curcumin (diferuloloymethane), (B) demethoxycurcumin and (C) bisdemethyoxycurcumin.

\section{Chemical composition}

Curcumoids consist of two methoxylated phenols connected through two $\alpha, \beta$-unsaturated carbonyl groups. Curcumin is rich in terpene derivates and contains predominantly monocyclic sesquiterpenes and oxygenated derivatives, such as turmerone and zingibrene (17). The rhizome contains 3-5\% curcuminoids and $2-7 \%$ essential oil $(18,19)$. Curcumin does not readily dissolve in water, whereas it is soluble in organic solvents, such as dimethyl sulfoxide, ethanol, methanol or acetone, and has a melting point of $183^{\circ} \mathrm{C}$. Curcumin presents a maximum spectrophotometric absorption of $430 \mathrm{~nm}$ in methanol and 415-420 nm in acetone, while a $1 \%$ solution of curcumin has 1,650 absorbance units (20).

\section{Anti-inflammatory activity}

Molecular studies have indicated that curcumin blocks the activation of factors or enzymes present in human cells able to trigger the inflammatory response. For instance, Surh et al revealed that curcumin is able to inhibit the activity and induced expression of cyclooxygenase-2 (COX-2) in various cell lines and animal models $(21,22)$.

Topical application of curcumin inhibits the lipopolysaccharide (LPS)-mediated induction of COX-2 expression. This effect, rather than the catalytic inhibition of COX, may contribute towards the reduced formation of prostaglandin $\mathrm{E}_{2}$ $\left(\mathrm{PGE}_{2}\right)$, while in macrophages not stimulated by LPS, curcumin increases the levels of COX-2 (23). Zhang et al observed that curcumin suppresses the expression of $\mathrm{COX}-2$ protein and mRNA, in addition to TPA- or chenodeoxycholate-induced $\mathrm{PGE}_{2}$ production (24). Furthermore, curcumin reduces the expression levels of COX-2 and $\mathrm{PGE}_{2}$ synthase 1 , which act on the $\mathrm{PGE}_{2}$ formation, and prostaglandin, which serves a key function in inflammation and tumor development. Curcumin was also demonstrated to reversibly inhibit the conversion of prostaglandin $\mathrm{H}_{2}\left(\mathrm{PGH}_{2}\right)$ to $\mathrm{PGE}_{2}$ by microsomal $\mathrm{PGE}_{2}$ synthase 1 in A549 lung cancer cells stimulated with interleukin (IL) $1 \beta$, with a half maximal inhibitory concentration between 0.2 and $0.3 \mu \mathrm{mol} \cdot \mathrm{L}^{-1}(25)$ In human whole blood stimulated with LPS, curcumin inhibits the formation of $\mathrm{PGE}_{2}$ by COX-2 from arachidonic acid (AA), while the formation of 6-keto $\mathrm{PGF}_{2 \alpha}$ and 12 (1)-hydroxy-5-cis- 8,10 -transeptadecatrienoico by COX-1 is suppressed at markedly higher concentrations (26). A previous study indicated that the deletion of microsomal $\mathrm{PGE}_{2}$ synthase 1 by curcumin is crucial to its anti-inflammatory and anticancer activities (26).

However, curcumoids exert a significant inhibitory effect on the peroxidase activity of COX-1, but not that of COX-2. In addition, curcumin and the curcumoids markedly inhibit the activity of 5-lipoxygenase (5-LOX), as curcumin interferes with the metabolism of AA by blocking cytosolic phospholipase $\mathrm{A}_{2}$ phosphorylation, and thus reducing the expression of COX-2 and inhibiting the catalytic activities of 5-LOX. These activities may to explain the anti-inflammatory action of curcumin and the curcumoids in general (23).

The inhibitory effects of curcumin on proinflammatory gene expression may be associated with its inactivation of activator protein-1 (AP-1) and nuclear factor- $\mathrm{KB}(\mathrm{NF}-\kappa \mathrm{B})(27) . N F-\kappa B$ and $A P-1$ are two transcription factor genes, which are overexpressed in cancer cells, and are crucial to the LPS-induced proinflammatory response. They control numerous cellular activities: NF- $\mathrm{\kappa B}$ mediates immune activity, inflammation, collagenase and cell proliferation, while AP-1 mediates cell proliferation $(3,28)$. By inhibiting NF- $\kappa B$, curcumin results in the death of malignant cells and inhibits inflammation (29).

Furthermore, AP-1 is involved in the activation of the stress-activated c-Jun N-terminal kinase (JNK), which is markedly expressed in various types of tumors, including head and neck, cervical and breast cancers. Curcumin is able to inhibit AP-1 signaling that is induced by tumor promoters by interacting with the AP-1 DNA-binding motif, in addition to inhibiting JNK activation by carcinogens (30).

In addition, NF- $\mathrm{KB}$ and AP-1 mediate the expression of inducible nitric oxide synthase (iNOS), and thus the production of nitric oxide (NO), COX, prostaglandins and tumor necrosis factor (TNF)- $\alpha$. These proinflammatory factors, in addition to the action of hypoxia through heterochromatin protein 1 (HF-1), AP-1 and various other co-factors, induce the expression of vascular endothelial growth factor (VEGF) and increase inflammation (31). VEGF may subsequently cause a metabolic cascade that leads to a degradation of the extracellular matrix (ECM), endothelial proliferation and ultimately angiogenesis $(32,33)$. Activation of NF- $\mathrm{kB}$ is elevated in numerous types of cancer, and is associated with various steps in the development of malignancy. Curcumin may exert a scavenger action directly against free radicals, and modulate the signaling pathways controlled by NF- $\mathrm{BB}$ and mitogen-activated protein kinase (MAP). In addition, curcumin reduces the expression of matrix metalloproteinases (MMPs), adhesion molecules and growth factors that stimulate the expression of histone deacetylase oxidized abnormally in the lung. Biswas and Rahman (34) indicated that curcumin may be a potential antioxidant and anti-inflammatory agent against chronic inflammatory diseases of the lung. In addition, Yadav et al (35) demonstrated that curcumin significantly inhibited the production of the proinflammatory cytokine, IL-18, which induces severe inflammatory reactions. 
Curcumin significantly inhibited the production of IL-18 in Escherichia coli LPS-stimulated murine macrophage-like RAW264.7 cells in a concentration-dependent manner, without exerting a cytotoxic effect (35).

\section{Effect on arthritis}

In Ayurvedic medicine, curcumin is used to treat inflammatory disorders, including arthritis, and is administered as a nutritional supplement. Funk et al (36) documented the effectiveness of an extract devoid of essential oils in preventing joint inflammation, while a hydroalcoholic extract of turmeric was demonstrated to inhibit joint inflammation and periarticular tissue destruction in a dose-dependent manner (37).

A recent study indicated that oral administration of curcumin was able to attenuate the neutrophil inflammatory response against zymosan-induced arthritis in rats (38). Furthermore, Panahi et al argued that curcuminoid treatment represents an effective and safe alternative treatment for osteoarthritis (39).

\section{Antiplatelet activity}

Curcumin inhibits the production of thromboxane (TX) by platelets in vitro and ex vivo and increases fibrinolysis. In addition, it inhibits platelet aggregation in vitro and ex vivo induced by ADP, collagen or norepinephrine (effective as aspirin) without decreasing the synthesis of prostacyclin in the epithelium aortic arch (the opposite of aspirin). With this differential action on prostacyclin, a progressive increase in doses of curcumin protects against collagen or norepinephrine-induced thrombosis (40).

The hydroalcoholic extract of turmeric inhibits platelet aggregation in vitro induced by AA instead of ADP or collagen, increases fibrinolysis, inhibits the production of TX by exogenous AA, and inhibits the release of AA. The cause of these actions may involve the inhibition of TX synthase. By contrast, the essential oil of turmeric does not exhibit any evident anti-platelet activity (41). In addition, Liu et al observed that the combination of curcumin and clopidogrel (antiplatelet family of thienopyridines) had no significant effect on the maximum platelet aggregation rate of rats compared with the use of clopidogrel alone (42).

\section{Antioxidant activity}

The antioxidant activities of curcuminoids are a result of their chemical composition. Curcumin inhibits lipid peroxidation using linoleate, a polyunsaturated fatty acid that is able to oxidize and form fatty acid radicals. Curcuminoids markedly reduce the hemolysis and lipid peroxidation of erythrocytes (lower vitamin E levels), and function as a scavenger of NO by blocking the enzyme that produces it, thus exerting a promoter activity (43). NO is a lipophilic molecule with a short half-life that is generated from L-arginine by various NADPH-dependent enzymes, known as NO synthases $(44,45)$. NO is involved physiologically in vasorelaxation, neurotransmission, inhibition of platelet aggregation, immunity and intracellular signaling $(44,45)$.

Additional studies have evaluated the potential use of curcumin in the prevention of neurodegenerative diseases, such as Alzheimer's disease. Oxidative damage and inflammatory processes are known to be particularly high in the brains of Alzheimer patients, and as the aqueous extract of turmeric reduces and prevents oxidation, it may be used concurrently in long-term therapy (46-49).

Motterlini et al confirmed that curcumin promotes the increased expression of heme oxygenase-1 (HO-1), an enzyme that catalyzes the degradation of heme and produces biliverdin, iron and carbon monoxide and exhibits cytoprotective activity against oxidative stress (50). Beneficial effects were also obtained using a mixture of curcuminoids that are commonly used as a nutritional supplement, particularly curcumin-95. The expression of HO-1 is increased in astrocytes treated with curcumin at 5-15 $\mu \mathrm{M}$ concentrations (51).

Recently, Miao et al described the beneficial effects of curcumin as an antioxidant and investigated the underlying mechanisms in diabetic rat model (52). In addition, Liu et al demonstrated that curcumin and resveratrol were able to regulate drug-metabolizing enzymes in addition to antioxidative enzymes during lung carcinogenesis in mice (53).

\section{Hepatoprotective action}

An in vivo study examined the protective effect of curcumin on the hepatotoxicity induced by carbon tetrachloride $\left(\mathrm{CCl}_{4}\right)(54)$. When administered at a dose of $3 \mathrm{ml} / \mathrm{kg} /$ day for three months, $\mathrm{CCl}_{4}$ caused a marked increase in transaminases, alkaline phosphatase and plasma levels of $\gamma$-glutamyl transpeptidase thiobarbituric acid and lipoperoxide, and a reduction in plasma levels of glutathione, vitamins $\mathrm{C}$ and $\mathrm{E}$. In addition, the liver and kidneys exhibited marked increases in thiobarbituric acid and lipoperoxide levels and an evident reduction in the levels of glutathione, vitamin $\mathrm{C}$ and vitamin $\mathrm{E}$. The administration of curcumin with $\mathrm{CCl}_{4}$ significantly reduced these phenomena in the plasma, kidneys and liver (54). In addition, the authors observed histological damage in these organs, with thickening of the portal vessels and the deposition of fat droplets in the vessel walls (54). An additional study indicated that curcumin prevents $\mathrm{CCl}_{4}$-induced liver damage by inhibiting the activation of $\mathrm{NF}-\kappa \mathrm{B}$ and exerting an antioxidative effect (55).

A previous study demonstrated that curcumin does not alter the levels and activity of cytochrome $\mathrm{P} 450$ in the liver, except at high doses of $\geq 5 \mathrm{~g} / \mathrm{kg} /$ day (56). Instead, $\mathrm{CCl}_{4}$ caused a marked reduction in the activity of these isoenzymes, particularly of cytochrome P450 2E1 (CYP2E1), with the formation of high levels of free radicals. Pretreatment with curcumin at a dose of $0.5 \mathrm{~g} / \mathrm{kg} /$ day significantly reduced the effects of $\mathrm{CCl}_{4}$ on these isoenzymes, but not on CYP2E1, possibly due to its marked antioxidative activity. Furthermore, the study indicated that the protection of the liver guaranteed by curcumin against $\mathrm{CCl}_{4}$-induced damage may depend, at least in part, on its contrasting effects against damage caused by $\mathrm{CCl}_{4}$ to cytochrome P450 (56).

\section{Anticancer activity}

A number of activities of curcumin, which are exerted in a chemopreventive and a directly therapeutic manner, indicate that it may be a potential anticancer remedy. Although the results have been obtained in animal models, curcumin has been 
demonstrated to be active in various other in vitro models, and the dosages are comparable to those used in humans. In vitro and in vivo studies have indicated that curcumin prevents carcinogenesis by affecting two primary processes: Angiogenesis and tumor growth (57).

Turmeric and curcuminoids influence tumor angiogenesis through multiple, interdependent processes (58): i) Action at the level of transcription factors NF- $\mathrm{KB}, \mathrm{AP}-1$ (associated with inflammatory processes) and early growth response protein 1 , which attenuates the expression of IL-8 in pancreatic and head and neck cancer cell lines and prevents the induction of VEGF synthesis; ii) inhibition of angiogenesis mediated by NO and iNOS; iii) inhibition of COX-2 and 5-LOX; iv) action at the level of angiogenic factors: VEGF, the primary factor for migration, sprouting, survival and proliferation during angiogenesis, and basic fibroblast growth factor; and v) action at the level of stability and coherence of the ECM, including the downregulation of MMP-2 and MMP-9, and upregulation of tissue inhibitor of metalloproteinase-1. Turmeric also interferes with the release of angiogenic factors stored in the ECM (58).

Curcumin induces cell death in numerous animal and human cell lines, including leukemia, melanoma, and carcinomas of the breast, lung, colon, kidney, ovaries and liver (59). It appears to function by caspase-dependent and independent (mitochondrial) mechanisms, which are associated with the presence and absence of p53. Certain data have demonstrated that curcumin exhibits a biphasic action, which acts on the proteasome, with an activation at lower doses and with inhibition at higher doses. As the inhibition of the proteasome leads to apoptosis, and its stimulation leads to cell survival, it is possible that curcumin results in apoptosis or survival depending on the dosage used. In addition, turmeric at different doses may also affect the type of cell death: Low doses lead to oxidative stress and apoptosis, while higher doses lead to reduced production of reactive oxygen species, reduction of ATP and necrotic cell death (60).

Curcumin also appears to be able to cause cell death in various cell lines resistant to apoptosis, possibly by activating cell death mechanisms other than apoptosis, such as mitotic catastrophe that is characterized by aberrant mitosis, and the formation of multinucleated and giant cells. The mitotic catastrophe caused by curcumin is linked to the reduction of gene expression of various apoptotic inhibitor proteins, in particular survivin (61).

Furthermore, a previous study demonstrated that curcumin administration was able to significantly reduce the levels of the cell cycle regulators CDK4 and cylin D1, and inhibit the expression of $\mathrm{p} 53$, which is an upstream regulator of the CDK4-cylin D1 complex (62). Recently, Vallianou et al (63) discussed the ability of curcumin to cause apoptosis in tumor cells by inducing severe endoplasmic reticulum stress, which serves a crucial function in the apoptotic process. The study suggested that curcumin may act by suppressing specific protein 1 activation and consequently was unable to prevent cancer formation, migration and invasion (63).

\section{Liver cancer}

Curcumin has been demonstrated to impede the formation of hepatic hyperplastic nodules, hypoproteinemia and body weight loss in Wistar rats (64). In an animal experiment,
$\mathrm{N}$-nitrosodimethylamine (DENA), a powerful hepatocarcinogen, was injected intraperitoneally in five-week-old $\mathrm{C} 3 \mathrm{H} / \mathrm{HeN}$ mice (64). One group of mice received a diet containing $0.2 \%$ curcumin, from 4 days prior to DENA injection until the end of the study. At the age of 42 weeks, the curcumin group exhibited an $81 \%$ reduction in the multiplicity and a $62 \%$ reduction in the incidence of hepatocarcinoma compared with the non-treated group (64). Busquets et al studied the chemopreventive potential of curcumin in rats that were inoculated with Yoshida AH-130 ascites hepatoma, a fast-growing tumor that results in fatality in $\sim 10$ days after inoculation (65). Curcumin significantly decreased tumor growth by $31 \%$ (21).

\section{Skin carcinogenesis}

Topical application of curcumin combined with the tumor promoter TPA, twice per week for 20 weeks, to female CD-1 mice markedly inhibited papilloma formation (66). In an additional study, topical application of relatively low doses of curcumin (20 or $100 \mathrm{nmol}$ ) markedly abrogated TPA-induced tumor promotion. Topical application of commercial-grade curcumin (containing $77 \%$ curcumin, $17 \%$ demethoxycurcumin and $3 \%$ bis-demethoxycurcumin), pure curcumin or demethoxycurcumin exhibited almost equipotent inhibitory effects on TPA-induced tumor promotion in DMBA-initiated mouse skin carcinogenesis. Furthermore, in female Swiss mice dietary administration of $2 \%$ turmeric significantly inhibited DMBA and TPA-induced skin tumor formation. In a benzo[a]pyrene-initiated and TPA-promoted two-stage skin tumorigenesis model, curcumin reduced the number of tumors per mouse and decreased the number of tumor-bearing mice. In further studies, Huang et al demonstrated that curcumin inhibited UV-induced dermatitis in mouse skin (67-69).

Jiang et al demonstrated that curcumin is able to induce apoptosis and inhibit the proliferation of melanoma cells (70). In addition, curcumin treatment altered the expression levels of the apoptosis-associated proteins, NF- $\mathrm{B}, \mathrm{p} 38$ and p53 (70).

\section{Pancreatic cancer}

In a xenograft model study, pancreatic cancer cells were injected subcutaneously into the side of the abdomen of female nude mice (71). Subsequently, liposomal curcumin was injected into these animals. This treatment reduced tumor size and decreased the expression of CD31 in addition to that of VEGF and IL-8, indicating that curcumin suppressed pancreatic carcinoma growth in murine xenograft models and inhibited tumor angiogenesis (71).

Bao et al demonstrated that the administration of difluorinated-curcumin (CDF) inhibited tumor growth in a manner associated with the reduced expression levels of EZH2, Notch-1, CD44, EpCAM and NANOG and increased expression levels of let-7, miR-26a and miR-101, which are typically not expressed in pancreatic cancer (72).

Furthermore, Ali et al demonstrated that the administration of CDF induced the re-expression of let-7, resulting in decreased tumor growth and Ras gene expression in pancreatic cancer cells (73). 


\section{Prostate cancer}

Androgen-dependent LNCaP prostate cancer cells were injected subcutaneously into mice fed with a $2 \%$ curcumin containing diet for up to 6 weeks (74). Curcumin significantly increased the extent of apoptosis, as measured by an in situ cell death assay, and caused a reduction in cell proliferation, as measured by a BrdU incorporation assay (74). In addition, curcumin has been observed to induce a marked reduction in MMP-2 and MMP-9 activity in tumor-bearing sites. A previous study demonstrated significantly fewer metastatic nodules in a curcumin-treated group compared with the untreated group (75).

Another study employed a xenograft prostate cancer model to evaluate the anti-tumor, radiosensitizing and chemosensitizing effect of curcumin (76). Prostate cancer cells were injected into the left inguinal area of nude mice, and curcumin was administered by gavage, while gemcitabine was introduced by intraperitoneal injection. Reduced expression of the $M d m 2$ oncogene was detected in xenografts treated with curcumin alone, in addition to those treated with combinations of curcumin and gemcitabine or irradiation (76). Furthermore, researchers have demonstrated that GO-Y030, a curcumin analogue, reduced the expression of Bcl-XL in prostate cancer (77).

\section{Ovarian cancer}

In order to evaluate the effect of curcumin against ovarian cancer, a group of animals were treated with curcumin alone or in combination with docetaxel (78). Curcumin alone induced a 49-55\% reduction in mean tumor growth compared with control animals, while the combination of curcumin with docetaxel resulted in a 77\% reduction in mean tumor growth compared with the controls. In both cases, curcumin induced a decrease of proliferation and microvessel density and a significant increase in tumor cell apoptosis (78). In a recent in vitro study, the authors showed that the combination of curcumin and triptolide was able to synergistically inhibit ovarian cancer cell growth (79).

\section{Lung cancer}

In an animal study the administration of curcumin decreased the number of lung tumor nodules and inhibited lung metastasis of melanoma (78). Therefore, it is possible to use curcumin in order to arrest the metastatic growth of tumor cells. In addition, exposure of lung cells to curcumin was demonstrated to inhibit cigarette smoke-induced NF- $\mathrm{\kappa B}$ activation, which correlated with the suppression of CS-induced cyclin D1, COX-2 and MMP-9 expression (78). Yang et al (80) observed that curcumin is able to inhibit cell proliferation, modifying the expression of proliferative and anti-proliferative proteins (survivin, $\mathrm{Bcl}-\mathrm{XL}$ and cyclin $\mathrm{B} 1$ ), cell cycle, migration and invasion, downregulating the invasive proteins VEGF, MMP-2, MMP-7 and intercellular adhesion molecule-1. Furthermore, curcumin appeared to reduce angiogenesis through suppression of the STAT3 signaling pathway in small cell lung cancer (80).

\section{Head and neck cancer}

Curcumin administration $(0.5 \mathrm{~g} / \mathrm{kg})$ in male $\mathrm{F} 344$ rats caused a $91 \%$ reduction in the frequency of 4-nitroquinoline 1-oxide-induced tongue carcinoma, with a marked reduction in the incidence of oral preneoplastic lesions (81). Azuine et al (82) used a Syrian golden hamster model to demonstrate that curcumin, alone or in combination with catechin, inhibited methyl(acetoxymethyl)nitrosamine-induced oral mucosal tumors. In addition, treatment with $10 \mathrm{mmol}$ curcumin caused reductions in the visible oral papillomas and papilloma volume of 39.6 and $61.3 \%$, respectively (82). Furthermore, treatment with curcumin caused a reduction in the incidence of oral squamous cell carcinoma (SCC), and the number of oral SCC lesions decreased by $51.3 \%$ (30). Following curcumin treatment, a reduction of the tumor proliferation index in hyperplasia, dysplasia and papilloma was observed (83).

Chakravarti et al indicated that curcumin is able to suppress the growth of immortalized oral mucosal epithelial cells and squamous cell carcinoma cells, while exerting minimal effects on normal oral epithelial cells (84). In SAS oral cancer cells, curcumin induced the promoter activity of insulin-like growth factor binding protein-5 and CCAAT/enhancer-binding protein $\alpha$, which are involved in the suppression of head and neck cancer. Curcumin exerted an inhibitory effect on these factors through the activation of $\mathrm{p} 38$, and resulted in decreased in vivo tumorigenesis in a mouse xenograft model (85). The activity of curcumin has been investigated in a number of head and neck SCC (HNSCC) cell lines, including CAL27, CCL23 (laryngeal), UM-SCC1 and UMSCC14A (oral) (86). The growth suppression effect was represented primarily by the effect of curcumin on the NF- $\kappa B$ signaling pathway. Curcumin caused a reduction in the expression of NF- $\mathrm{KB}$ and, in addition, inhibited its nuclear localization. The activity of curcumin on the NF- $\kappa B$ in this type of tumor is due to inhibition of IкB kinase (IKK), thus blocking the phosphorylation of IкB- $\alpha$ and resulting in NF- $\kappa B$ sequestration in the cytoplasm (87). It has been demonstrated that the inhibition of IKK occurs via an AKT-independent mechanism (87). AKT, also known as protein kinase $\mathrm{B}$, is involved in signal transduction from oncogenes and growth factors. The effects of curcumin on the AKT signaling pathway are various: In certain tumors, including malignant gliomas and pancreatic cancer, curcumin suppresses the AKT signaling pathway, whereas in HNSCCs and melanoma, it has been demonstrated that curcumin functions independent of AKT (88). The AKT signaling cascade is stimulated by epidermal growth factor receptor (EGFR) and represents one pathway by which NF- $\kappa \mathrm{B}$ may be activated (89). EGFR is overexpressed in numerous types of head and neck cancer, and molecular therapies targeting the EGFR/AKT signaling cascade the therapeutic efficacy of standard platinum-based chemotherapy (90). In addition, the expression levels of multiple NF-kB-regulated gene products, including IL-6, IL-8, MMP-9, COX-2, CCL2 and Bcl-XL, were reduced (86,91-95).

Additionally, in a study using a mouse model of SCC-1 tumors, curcumin was shown to decrease COX-2 expression and inhibit EGFR phosphorylation (96). In other types of tumors, including prostate, colorectal and ovarian, the use of curcumin as a radiosensitizer has been supported in prostate, colorectal and ovarian cancers, in addition to HNSCC $(97,98)$.

Several studies have demonstrated the potential use of curcumin as an adjuvant compound in combination with standard platinum-based chemotherapy for the treatment of head and neck tumors (96). In particular, a basic component of 
curcumin, known as FLL32, is able to increase the effectiveness of this type of chemotherapy-regressing tumor cells by inhibiting STAT3 phosphorylation, reducing survival signaling, and increasing susceptibility to apoptosis and sensitization to cisplatin (99).

The potential anti-cancer properties of curcumin have been widely investigated; however, the spice it contained is not able to be absorbed by the body. By contrast, FLL32 is easily assimilated and able to sensitize cancer cell lines that are resistant to platinum-based chemotherapy. In order to eliminate cancer cells that are resistant to cisplatin, it may be necessary to increase the dose of chemotherapy, which entails increased risk. The use of FLL32 to sensitize such cells may reduce the required dose of cisplatin, and therapy may therefore be conducted with reduced toxicity and potential damage to the body (99).

Numerous studies have demonstrated that, in vivo, curcumin exerts growth suppressive effects, using nude mouse xenograft models $(81,82,100,101)$. Clark et al observed an inhibited tumor growth in mice, via the inhibition of the AKT/MTOR pathway, following treatment with an oral curcumin solution prior to inoculation of SCC40 tongue SCC cells (102). In addition, Chang et al demonstrated the suppression of oral carcinogenesis in mice xenografts (85). Furthermore, Kumar et al (103) developed a novel class of curcumin analogs (H-4073), based on diarylidenylpiperidones (DAP), incorporating a piperidone link to the $\beta$-diketone structure and fluoro-substitutions on the phenyl groups. These authors demonstrated the potent anti-tumor effects of H-4073, a parafluorinated variant of DAP, using in vitro and in vivo head and neck cancer models (103).

Curcumin may also have a potential application as an enhancer of radiation therapy. Rao et al (104) compared the effects of curcumin and single-dose radiation alone and in combination in the HNSCC cell lines SCC-1, SCC-9, A431 and KB. The results demonstrated that curcumin inhibited HNSCC cell growth and augmented the effect of radiation in vitro and in vivo. The underlying mechanism may have involved the inhibition of COX-2 expression and EGFR phosphorylation.

In a recent study in vitro, the authors confirmed that curcumin used in combination with AG490, a JAK-2 inhibitor, reduced the expression of JAK-2/STAT-3 in laryngeal squamous cell carcinoma. In particular, the expression of JAK-2, p-STAT3, MMP-2 and VEGF at the protein levels were decreased $(\mathrm{P}<0.01)(105)$. Another study hypothesized that $\mathrm{H}-4073$, an analog of curcumin, may be useful as an anticancer agent for mitigating resistance to chemotherapy in patients with HNSCCs (103).

\section{Conclusion}

Curcumin (diferuloylmethane) is a polyphenol derived from the Curcuma longa plant that has numerous therapeutic properties, including antioxidative, analgesic, anti-inflammatory and antiseptic activities. Recently, a number of studies have indicated the anticancer activities of curcumin by investigating its effect on a variety of biological pathways involved in mutagenesis, apoptosis, tumorigenesis, cell cycle regulation and metastasis.

The results reviewed in the current study indicated that curcumin may exert positive effects against various types of tumor. Notably, combination of curcumin with other nutraceuticals, such as resveratrol, have been used to combat the mechanism underlying tumorigenesis, and the prevalence of studies have employed curcumin analogues as effective potential treatments.

Therefore, further in vivo studies elucidating the mechanisms underlying the effects of this nutraceutical may be useful in the treatment of tumors and elimination of the use of cancer treatments that have known side effects.

\section{References}

1. Takahashi M, Ishiko T, Kamohara H, Hidaka H, Ikeda O, Ogawa $\mathrm{M}$ and Baba $\mathrm{H}$ : Curcumin (1,7-bis(4-hydroxy-3-meth oxyphenyl)-1,6-heptadiene-3,5-dione) blocks the chemotaxis of neutrophils by inhibiting signal transduction through IL-8 receptors. Mediators Inflamm 2007: 10767, 2007.

2. Jurenka JS: Anti-inflammatory properties of curcumin, a major constituent of Curcuma longa: A review of preclinical and clinical research. Altern Med Rev 14: 141-153, 2009.

3. Wilken R, Veena MS, Wang MB and Srivatsan ES: Curcumin: A review of anti-cancer properties and therapeutic activity in head and neck squamous cell carcinoma. Mol Cancer 10: 12, 2011.

4. Miłobędzka J, Kostanecki S and Lampe V: Notes on Curcumins. Ber Deut Chem Ges 43: 2163-2170, 1910 (In German).

5. Sharma RA, Gescher AJ and Steward WP: Curcumin: The story so far. Eur J Cancer 41: 1955-1968, 2005.

6. Sandur SK, Pandey MK, Sung B, Ahn KS, Murakami A, Sethi G, Limtrakul P, Badmaev V and Aggarwal BB: Curcumin, demethoxycurcumin, bisdemethoxycurcumin, tetrahydrocurcumin and turmerones differentially regulate anti-inflammatory and anti-proliferative responses through a ROS-independent mechanism. Carcinogenesis 28: 1765-1773, 2007.

7. Gupta SC, Kismali G and Aggarwal BB: Curcumin, a component of turmeric: From farm to pharmacy. Biofactors 39: 2-13, 2013.

8. Kumar A, Ahuja A, Ali J and Baboota S: Conundrum and therapeutic potential of curcumin in drug delivery. Crit Rev Ther Drug Carrier Syst 27: 279-312, 2010.

9. Ammon HP and Wahl MA: Pharmacology of Curcuma longa. Planta Med 57: 1-7, 1991.

10. Lev-Ari S, Strier L, Kazanov D, Elkayam O, Lichtenberg D, Caspi D and Arber N: Curcumin synergistically potentiates the growth-inhibitory and pro-apoptotic effects of celecoxib in osteoarthritis synovial adherent cells. Rheumatology (Oxford) 45: 171-177, 2006.

11. Neerati P, Devde R and Gangi AK: Evaluation of the effect of curcumin capsules on glyburide therapy in patients with type-2 diabetes mellitus. Phytother Res 28: 1796-1800, 2014.

12. Kim YS, Young MR, Bobe G, Colburn NH and Milner JA: Bioactive food components, inflammatory targets and cancer prevention. Cancer Prev Res (Phila) 2: 200-208, 2009.

13. Bhullar KS, Jha A, Youssef D and Rupasinghe HP: Curcumin and its carbocyclic analogs: Structure-activity in relation to antioxidant and selected biological properties. Molecules 18: 5389-5404, 2013.

14. Somchit M, Changtam C, Kimseng R, Utaipan T, Lertcanawanichakul M, Suksamrarn A and Chunglok W: Demethoxycurcumin from Curcuma longa rhizome suppresses iNOS induction in an in vitro inflamed human intestinal mucosa model. Asian Pac J Cancer Prev 15: 1807-1810, 2014.

15. Li YB, Gao JL, Zhong ZF, Hoi PM, Lee SM and Wang YT: Bisdemethoxycurcumin suppresses MCF-7 cells proliferation by inducing ROS accumulation and modulating senescence-related pathways. Pharmacol Rep 65: 700-709, 2013.

16. Food and Drug Administration (FDA): Food for Human Consumption; Part 182 - Substances generally recognized as safe. http://accessdata.fda.gov/scripts/cdrh/cfdocs/cfcfr/CFRSearch. cfm?fr=182.10. Accessed, 2011.

17. Aggarwal BB, Deb L and Prasad S: Curcumin differs from tetrahydrocurcumin for molecular targets, signaling pathways and cellular responses. Molecules 20: 185-205, 2014.

18. Masuda T, Hidaka K, Shinohara A, Maekawa T, Takeda Y and Yamaguchi H: Chemical studies on antioxidant mechanism of curcuminoid: Analysis of radical reaction products from curcumin. J Agric Food Chem 47: 71-77, 1999.

19. Wang YJ, Pan MH, Cheng AL, Lin LI, Ho YS, Hsieh CY and Lin JK: Stability of curcumin in buffer solutions and characterization of its degradation products. J Pharm Biomed Anal 15: 1867-1876, 1997. 
20. Prasad K, Mantha SV, Kalra J and Lee P: Prevention of hypercholesterolemic atherosclerosis by garlic, an antixoidant. J Cardiovasc Pharmacol Ther 2: 309-320, 1997.

21. Surh YJ and Chun KS: Cancer chemopreventive effects of curcumin. Adv Exp Med Biol 595: 149-172, 2007.

22. Surh YJ, Chun KS, Cha HH, Han SS, Keum YS, Park KK and Lee SS: Molecular mechanisms underlying chemopreventive activities of anti-inflammatory phytochemicals: Down-regulation of COX-2 and iNOS through suppression of NF-kappaB activation. Mutat Res 480-481: 243-268, 2001

23. Hong J, Bose M, Ju J, Ryu JH, Chen X, Sang S, Lee MJ and Yang CS: Modulation of arachidonic acid metabolism by curcumin and related beta-diketone derivatives: Effects on cytosolic phospholipase A (2), cyclooxygenases and 5-lipoxygenase. Carcinogenesis 25: 1671-1679, 2004.

24. Zhang F, Altorki NK, Mestre JR, Subbaramaiah K and Dannenberg AJ: Curcumin inhibits cyclooxygenase-2 transcription in bile acid- and phorbol ester-treated human gastrointestinal epithelial cells. Carcinogenesis 20: 445-451, 1999.

25. Li Y, Zhang S, Geng JX and Hu XY: Curcumin inhibits human non-small cell lung cancer A549 cell proliferation through regulation of $\mathrm{Bcl}-2 / \mathrm{Bax}$ and cytochrome $\mathrm{C}$. Asian Pac J Cancer Prev 14:4599-4602,2013

26. Koeberle A, Northoff $\mathrm{H}$ and Werz O: Curcumin blocks prostaglandin E2 biosynthesis through direct inhibition of the microsomal prostaglandin E2 synthase-1. Mol Cancer Ther 8: 2348-2355, 2009.

27. Divya CS and Pillai MR: Antitumor action of curcumin in human papillomavirus associated cells involves downregulation of viral oncogenes, prevention of NF-kB and AP-1 translocation and modulation of apoptosis. Mol Carcinog 45: 320-332, 2006.

28. Hess J, Angel P and Schorpp-Kistner M: AP-1 subunits: Quarre and harmony among siblings. J Cell Sci 117: 5965-5973, 2004.

29. Panicker SR and Kartha CC: Curcumin attenuates glucose-induced monocyte chemoattractant protein-1 synthesis in aortic endothelial cells by modulating the nuclear factor-kappaB pathway. Pharmacology 85: 18-26, 2010.

30. Aggarwal BB, Sundaram C, Malani $\mathrm{N}$ and Ichikawa $\mathrm{H}$ : Curcumin: The Indian solid gold. Adv Exp Med Biol 595: 1-75, 2007.

31. Huang YF, Zhu XX, Ding ZS and Lv GY: Study on anti-angiogenesis effect of three curcumin pigments and expression of their relevant factors. Zhongguo Zhong Yao Za Zhi 40: 324-329, 2015 (In Chinese).

32. Arbiser JL, Klauber N, Rohan R, van Leeuwen R, Huang MT, Fisher C, Flynn E and Byers HR: Curcumin is an in vivo inhibitor of angiogenesis. Mol Med 4: 376-383, 1998.

33. Gururaj AE, Belakavadi M, Venkatesh DA, Marmé D and Salimath BP: Molecular mechanisms of anti-angiogenic effect of curcumin. Biochem Biophys Res Commun 297: 934-942, 2002.

34. Biswas S and Rahman I: Modulation of steroid activity in chronic inflammation: A novel anti-inflammatory role for curcumin. Mol Nutr Food Res 52: 987-994, 2008.

35. Yadav R, Jee B and Awasthi SK: Curcumin suppresses the production of pro-inflammatory cytokine interleukin-18 in lipopolysaccharide stimulated murine macrophage-like cells Indian J Clin Biochem 30: 109-112, 2015.

36. Funk JL, Oyarzo JN, Frye JB, Chen G, Lantz RC, Jolad SD, Sólyom AM and Timmermann BN: Turmeric extracts containing curcuminoids prevent experimental rheumatoid arthritis. J Nat Prod 69: 351-355, 2006.

37. Funk JL, Frye JB, Oyarzo JN, Kuscuoglu N, Wilson J, McCaffrey G, Stafford G, Chen G, Lantz RC, Jolad SD, et al: Efficacy and mechanism of action of turmeric supplements in the treatment of experimental arthritis. Arthritis Rheum 54 3452-3464, 2006

38. Nonose N, Pereira JA, Machado PR, Rodrigues MR, Sato DT and Martinez CA: Oral administration of curcumin (Curcuma longa) can attenuate the neutrophil inflammatory response in zymosan-induced arthritis in rats. Acta Cir Bras 29: 727-734, 2014

39. Panahi Y, Rahimnia AR, Sharafi M, Alishiri G, Saburi A and Sahebkar A: Curcuminoid treatment for knee osteoarthritis: A randomized double-blind placebo-controlled trial. Phytother Res 28: 1625-1631, 2014.

40. Srivastava R, Dikshit M, Srimal RC and Dhawan BN Anti-thrombotic effect of curcumin. Trhomb Res 40: 413-417, 1985.
41. Shah BH, Nawaz Z, Pertani SA, Roomi A, Mahmood H, Saeed SA and Gilani AH: Inhibitory effect of curcumin, a food spice from turmeric, on platelet-activating factor- and arachidonic acid-mediated platelet aggregation through inhibition of thromboxane formation and $\mathrm{Ca}^{2+}$ signaling. Biochem Pharmacol 58 $1167-1172,1999$.

42. Liu AC, Zhao LX and Lou HX: Curcumin alters the pharmacokinetics of warfarin and clopidogrel in Wistar rats but has no effect on anticoagulation or antiplatelet aggregation. Planta Med 79: 971-977, 2013.

43. Lala PK and Chakraborty C: Role of nitric oxide in carcinogenesis and tumour progression. Lancet Oncol 2: 149-156, 2001.

44. deRojas-WalkerT, Tamir S, JiH, Wishnok JS and Tannenbaum SR Nitric oxide induces oxidative damage in addition to deamination in macrophage DNA. Chem Res Toxicol 8: 473-477, 1995.

45. Graziewicz M, Wink DA and Laval F: Nitric oxide inhibits DNA ligase activity: Potential mechanisms for NO-mediated DNA damage. Carcinogenesis 17: 2501-2505, 1996.

46. Mourtas S, Lazar AN, Markoutsa E, Duyyckaerts C and Antimisiaris SG: Multifunctional nanoliposomes with curcumin-lipid derivative and brain targeting functionality with potential applications for Alzheimer disease. Eur J Med Chem 80: 175-183, 2014

47. Fang L, Gou S, Liu X, Cao F and Cheng L: Design, synthesis and anti-Alzheimer properties of dimethylaminomethyl-substituted curcumin derivatives. Bioorg Med Chem Lett 24: 40-43, 2014.

48. Lazar AN, Mourtas S, Youssef I, Parizot C, Dauphin A, Delatour B Antimisiaris SG and Duyckaerts C: Curcumin-conjugated nanoliposomes with high affinity for $\mathrm{A} \beta$ deposits: Possible applications to Alzheimer disease. Nanomedicine 9: 712-721, 2013.

49. Belkacemi A, Doggui S, Dao L and Ramassamy C: Challenges associated with curcumin therapy in Alzheimer disease. Expert Rev Mol Med 13:e34,2011.

50. Motterlini R, Foresti R, Bassi R and Green CJ: Curcumin, an antioxidant and anti-inflammatory agent, induces heme oxygenase-1 and protects endothelial cells against oxidative stress. Free Radic Biol Med 28: 1303-1312, 2000.

51. Scapagnini G, Colombrita C, Amadio M, D'Agata V, Arcelli E, Sapienza M, Quattrone A and Calabrese V: Curcumin activates defensive genes and protects neurons against oxidative stress. Antioxid Redox Signal 8: 395-403, 2006.

52. Miao M, Guo L, Tian S and Wang T: Effects of curcumin on antioxidation in diabetic rats. Pak J Pharm Sci 28 (Suppl 1): 371-373, 2015.

53. Liu Y, Wu YM, Yu Y, Cao CS, Zhang JH, Li K and Zhang PY: Curcumin and resveratrol in combination modulate drug-metabolizing enzymes as well as antioxidant indices during lung carcinogenesis in mice. Hum Exp Toxicol 34: 620-627, 2015.

54. Kamalakkannan N, Rukkumani R, Varma PS, Viswanathan P, Rajasekharan KN and Menon VP: Comparative effects of curcumin and an analogue of curcumin in carbon tetrachloride-induced hepatotoxicity in rats. Basic Clin Pharmacol Toxicol 97: 15-21, 2005.

55. Reyes-Gordillo K, Segovia J, Shibayama M, Vergara P, Moreno MG and Muriel P: Curcumin protects against acute liver damage in the rat by inhibiting NF-kappaB, proinflammatory cytokines production and oxidative stress. Biochim Biophys Acta 1770: 989-996, 2007.

56. Sugiyama T, Nagata J, Yamagishi A, Endoh K, Saito M, Yamada K, Yamada S and Umegaki K: Selective protection of curcumin against carbon tetrachloride-induced inactivation of hepatic cytochrome P450 isozymes in rats. Life Sci 78: 2188-2193, 2006

57. Maheshwari RK, Singh AK, Gaddipati J and Srimal RC: Multiple biological activities of curcumin: A short review. Life Sci 78 2081-2087, 2006.

58. Yance DR Jr and Sagar SM: Targeting angiogenesis with integrative cancer therapies. Integr Cancer Ther 5: 9-29, 2006.

59. Karunagaran D, Rashmi R and Kumar TR: Induction of apoptosis by curcumin and its implications for cancer therapy. Curr Cancer Drug Targets 5: 117-129, 2005.

60. Helson L: Curcumin (diferuloylmethane) delivery methods: A review. Biofactors 39: 21-26, 2013.

61. Salvioli S, Sikora E, Cooper EL and Franceschi C: Curcumin in cell death processes: A challenge for CAM of age-related pathologies. Evid Based Complement Alternat Med 4: 181-190, 2007.

62. Yang JY, Zhong X, Yum HW, Lee HJ, Kundu JK, Na HK and Surh YJ: Curcumin inhibits STAT3 signaling in the colon of dextran sulfate sodium-treated mice. J Cancer Prev 18: 186-191, 2013. 
63. Vallianou NG, Evangelopoulos A, Schizas N and Kazazis C: Potential anticancer properties and mechanisms of action of curcumin. Anticancer Res 35: 645-651, 2015.

64. Chuang SE, Cheng AL, Lin JK and Kuo ML: Inhibition by curcumin of diethylnitrosamine-induced hepatic hyperplasia inflammation, cellular gene products and cell-cycle-related proteins in rats. Food Chem Toxicol 38: 991-995, 2000.

65. Busquets S, Carbó N, Almendro V, Quiles MT, López-Soriano FJ and Argilés JM: Curcumin, a natural product present in turmeric, decreases tumor growth but does not behave as an anticachectic compound in a rat model. Cancer Lett 167: 33-38, 2001.

66. Huang MT, Wang ZY, Georgiadis CA, Laskin JD and Conney AH: Inhibitory effects of curcumin on tumor initiation by benzo[a]pyrene and 7,12-dimethylbenz[a]anthracene. Carcinogenesis 13: 2183-2186, 1992.

67. Huang MT, Ma W, Lu YP, Chang RL, Fisher C, Manchand PS, Newmark HL and Conney AH: Effects of curcumin, demethoxycurcumin, bisdemethoxycurcumin and tetrahydrocurcumin on 12-O-tetradecanoylphorbol-13-acetate-induced tumor promotion. Carcinogenesis 16: 2493-2497, 1995.

68. Huang MT, Ma W, Yen P, Xie JG, Han J, Frenkel K, Grunberger D and Conney AH: Inhibitory effects of topical application of low doses of curcumin on 12-O-tetradecanoylphorbol-13-acetate-induced tumor promotion and oxidized DNA bases in mouse epidermis. Carcinogenesis 18: 83-88, 1997.

69. Huang MT, Smart RC, Wong CQ and Conney AH: Inhibitory effect of curcumin, chlorogenic acid, caffeic acid and ferulic acid on tumor promotion in mouse skin by $12-\mathrm{O}$-tetradecanoylphorbol-13-acetate. Cancer Res 48: 5941-5946, 1988.

70. Jiang AJ, Jiang G, Li LT and Zheng JN: Curcumin induces apoptosis through mitochondrial pathway and caspases activation in human melanoma cells. Mol Biol Rep 42: 267-275, 2015.

71. Li L, Braiteh FS and Kurzrock R: Liposome-encapsulated curcumin: In vitro and in vivo effects on proliferation, apoptosis, signaling and angiogenesis. Cancer 104: 1322-1331, 2005.

72. Bao B, Ali S, Banerjee S, Wang Z, Logna F, Azmi AS, Kong D, Ahmad A, Li Y, Padhye S and Sarkar FH: Curcumin analogue CDF inhibits pancreatic tumor growth by switching on suppressor microRNAs and attenuating EZH2 expression. Cancer Res 72: 335-345, 2012

73. Ali S, Ahmad A, Aboukameel A, Bao B, Padhye S, Philip PA and Sarkar FH: Increased Ras GTPase activity is regulated by miRNAs that can be attenuated by CDF treatment in pancreatic cancer cells. Cancer Lett 319: 173-181, 2012.

74. Dorai T, Cao YC, Dorai B, Buttyan R and Katz AE: Therapeutic potential of curcumin in human prostate cancer III. Curcumin inhibits proliferation, induces apoptosis and inhibits angiogenesis of LNCaP prostate cancer cells in vivo. Prostate 47: 293-303, 2001.

75. Hong JH, Ahn KS, Bae E, Jeon SS and Choi HY: The effects of curcumin on the invasiveness of prostate cancer in vitro and in vivo. Prostate Cancer Prostatic Dis 9: 147-152, 2006.

76. Li M, Zhang Z, Hill DL, Wang H and Zhang R: Curcumin, a dietary component, has anticancer, chemosensitization and radiosensitization effects by down-regulating the MDM2 oncogene through the PI3K/mTOR/ETS2 pathway. Cancer Res 67: 1988-1996, 2007

77. Yallapu MM, Dobberpuhl MR, Maher DM, Jaggi M and Chauhan SC: Design of curcumin loaded cellulose nanoparticles for prostate cancer. Curr Drug Metab 13: 120-128, 2012.

78. Menon LG, Kuttan R and Kuttan G: Inhibition of lung metastasis in mice induced by B16F10 melanoma cells by polyphenolic compounds. Cancer letters 95: 221-225, 1995.

79. Cai YY,Lin WP,Li AP and Xu JY: Combined effects of curcumin and triptolide on an ovarian cancer cell line. Asian Pac J Cancer Prev 14: 4267-4271, 2013

80. Yang CL, Liu YY, Ma YG, Xue YX, Liu DG, Ren Y, Liu XB, Li Y and Li Z: Curcumin blocks small cell lung cancer cells migration, invasion, angiogenesis, cell cycle and neoplasia through Janus kinase-STAT3 signalling pathway. PLoS One 7: e37960, 2012.

81. Tanaka T, Makita H, Ohnishi M, Hirose Y, Wang A, Mori H, Satoh K, Hara A and Ogawa H: Chemoprevention of 4-nitroquinoline 1-oxide-induced oral carcinogenesis by dietary curcumin and hesperidin: Comparison with the protective effect of beta-carotene. Cancer Res 54: 4653-4659, 1994.

82. Azuine MA and Bhide SV: Adjuvant chemoprevention of experimental cancer: Catechin and dietary turmeric in forestomach and oral cancer models. J Ethnopharmacol 44: 211-217, 1994.
83. Tomren MA, Másson M, Loftsson T and Tønnesen HH: Studies on curcumin and curcuminoids XXXI. Symmetric and asymmetric curcuminoids: Stability, activity and complexation with cyclodextrin. Int J Pharm 338: 27-34, 2007.

84. Chakravarti N, Kadara H, Yoon DJ, Shay JW, Myers JN, Lotan D, Sonenberg N and Lotan R: Differential inhibition of protein translation machinery by curcumin in normal, immortalized and malignant oral epithelial cells. Cancer Prev Res (Phila) 3: 331-338, 2010.

85. Chang KW, Hung PS, Lin IY, Hou CP, Chen LK, Tsai YM and Lin SC: Curcumin upregulates insulin-like growth factor binding protein-5 (IGFBP-5) and C/EBPalpha during oral cancer suppression. Int J Cancer 127: 9-20, 2010.

86.LoTempio MM, Veena MS, Steele HL, Ramamurthy B Ramalingam TS, Cohen AN, Chakrabarti R, Srivatsan ES and Wang MB: Curcumin suppresses growth of head and neck squamous cell carcinoma. Clin Cancer Res 11: 6994-7002, 2005.

87. Sandur SK, Deorukhkar A, Pandey MK, Pabón AM, Shentu S, Guha S, Aggarwal BB and Krishnan S: Curcumin modulates the radiosensitivity of colorectal cancer cells by suppressing constitutive and inducible NF-kappaB activity. Int J Radiat Oncol Biol Phys 75: 534-542, 2009.

88. Siwak DR, Shishodia S, Aggarwal BB and Kurzrock R: Curcumin-induced antiproliferative and proapoptotic effects in melanoma cells are associated with suppression of I kappaB kinase and nuclear factor kappaB activity and are independent of the B-Raf/mitogen-activated/extracellular signal-regulated protein kinase pathway and the Akt pathway. Cancer 104: 879-890, 2005.

89. Crowell JA, Steele VE and Fay JR: Targeting the AKT protein kinase for cancer chemoprevention. Mol Cancer Ther 6: 2139-2148, 2007.

90. Vermorken JB, Mesia R, Rivera F, Remenar E, Kawecki A, Rottey S, Erfan J, Zabolotnyy D, Kienzer HR, Cupissol D, et al: Platinum-based chemotherapy plus cetuximab in head and neck cancer. N Engl J Med 359: 1116-1127, 2008.

91. Aravindan N, Madhusoodhanan R, Ahmad S, Johnson D and Herman TS: Curcumin inhibits NF-kappaB mediated radioprotection and modulate apoptosis related genes in human neuroblastoma cells. Cancer Biol Ther 7: 569-576, 2008.

92. Bachmeier BE, Mohrenz IV, Mirisola V, Schleicher E, Romeo F, Höhneke C, Jochum M, Nerlich AG and Pfeffer U: Curcumin downregulates the inflammatory cytokines CXCL1 and -2 in breast cancer cells via NF-kappaB. Carcinogenesis 29: 779-789, 2008.

93. Marin YE, Wall BA, Wang S, Namkoong J, Martino JJ, Suh J, Lee HJ, Rabson AB, Yang CS, Chen S and Ryu JH: Curcumin downregulates the constitutive activity of NF-kappaB and induces apoptosis in novel mouse melanoma cells. Melanoma Res 17: 274-283, 2007.

94. Tomita M, Kawakami H, Uchihara JN, Okudaira T, Masuda M, Takasu N, Matsuda T, Ohta T, Tanaka Y, Ohshiro K and Mori N: Curcumin (diferuloylmethane) inhibits constitutive active NF-kappaB, leading to suppression of cell growth of human T-cell leukemia virus type I-infected T-cell lines and primary adult T-cell leukemia cells. Int J Cancer 118: 765-772, 2006.

95. Wang D, Veena MS, Stevenson K, Tang C, Ho B, Suh JD, Duarte VM, Faull KF, Mehta K, Srivatsan ES and Wang MB: Liposome-encapsulated curcumin suppresses growth of head and neck squamous cell carcinoma in vitro and in xenografts through the inhibition of nuclear factor kappaB by an AKT-independent pathway. Clin Cancer Res 14: 6228-6236, 2008.

96. Khafif A, Lev-Ari S, Vexler A, Barnea I, Starr A, Karaush V, Haif S and Ben-Yosef R: Curcumin: A potential radio-enhancer in head and neck cancer. Laryngoscope 119: 2019-2026, 2009.

97. Jagetia GC: Radioprotection and radiosensitization by curcumin . Adv Exp Med Biol 595: 301-320, 2007.

98. Yallapu MM, Maher DM, Sundram V, Bell MC, Jaggi M and Chauhan SC: Curcumin induces chemo/radio-sensitization in ovarian cancer cells and curcumin nanoparticles inhibit ovarian cancer cell growth. J Ovarian Res 3: 11, 2010.

99. Abuzeid WM, Davis S, Tang AL, Saunders L, Brenner JC, Lin J, Fuchs JR, Light E, Bradford CR, Prince ME and Carey TE: Sensitization of head and neck cancer to cisplatin through the use of a novel curcumin analog. Arch Otolaryngol Head Neck Surg 137: 499-507, 2011.

100. Li N, Chen X, Liao J, Yang G, Wang S, Josephson Y,Han C, Chen J, Huang MT and Yang CS: Inhibition of 7,12-dimethylbenz[a] anthracene (DMBA)-induced oral carcinogenesis in hamsters by tea and curcumin. Carcinogenesis 23: 1307-1313, 2002. 
101. Manoharan S, Balakrishnan S, Menon VP, Alias LM and Reena AR: Chemopreventive efficacy of curcumin and piperine during 7,12-dimethylbenz[a]anthracene-induced hamster buccal pouch carcinogenesis. Singapore Med J 50: 139-146, 2009.

102. Clark CA, McEachern MD, Shah SH, Rong Y, Rong X, Smelley CL, Caldito GC, Abreo FW and Nathan CO: Curcumin inhibits carcinogen and nicotine-induced Mammalian target of rapamycin pathway activation in head and neck squamous cell carcinoma. Cancer Prev Res (Phila) 3: 1586-1595, 2010.

103. Kumar B, Yadav A, Hideg K, Kuppusamy P, Teknos TN and Kumar P: A novel curcumin analog (H-4073) enhances the therapeutic efficacy of cisplatin treatment in head and neck cancer. PloS One 9: e93208, 2014.
104. Rao CV, Simi B and Reddy BS: Inhibition by dietary curcumin of azoxymethane-induced ornithine decarboxylase, tyrosine protein kinase, arachidonic acid metabolism and aberrant crypt foci formation in the rat colon. Carcinogenesis 14: 2219-2225, 1993.

105. Hu A, Huang JJ, Jin XJ, Li JP, Tang YJ, Huang XF, Cui HJ, $\mathrm{Xu} \mathrm{WH}$ and Sun GB: Curcumin suppresses invasiveness and vasculogenic mimicry of squamous cell carcinoma of the larynx through the inhibition of JAK-2/STAT-3 signaling pathway. Am J Cancer Res 5: 278-288, 2014. 